\title{
Partial Derivatives Involving Generalized I-Function of Two Variables
}

\author{
Shanti Swaroop Dubey ${ }^{1}$, Dr. S. S. Shrivastava ${ }^{2}$ \\ ${ }^{I}$ ITM University, Raipur (C. G.) \\ ${ }^{2}$ Institute for Excellence in Higher Education, Bhopal (M. P.)
}

Abstract: The aim of this paper is to derive partial derivatives involving generalized I-function of two variables.

\section{Introduction}

The generalized I-function of two variables introduced by Goyal and Agrawal [1], will be defined and represented as follows:

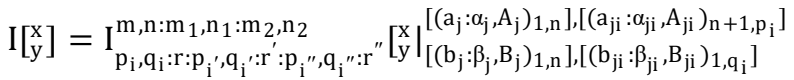

$$
\begin{aligned}
& :\left[\left(c_{j} ; \gamma_{j}\right)_{1, n_{1}}\right],\left[\left(c_{j i}{ }^{\prime} ; \gamma_{j i}{ }^{\prime}\right)_{n_{1}+1, p_{i}}\right] ;\left[\left(e_{j} ; E_{j}\right)_{1, n_{2}}\right],\left[\left(e_{j i}{ }^{\prime \prime} ; E_{j i}{ }^{\prime \prime}\right)_{n_{2}+1, p_{i}{ }^{\prime \prime}}\right]
\end{aligned}
$$

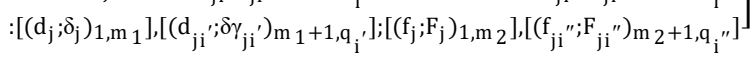

$$
\begin{aligned}
& =\frac{1}{(2 \pi \omega)^{2}} \int_{L_{1}} \int_{L_{2}} \phi_{1}(\xi, \eta) \theta_{2}(\xi) \theta_{3}(\eta) x^{\xi} y^{\eta} d \xi d \eta \text {, }
\end{aligned}
$$

where

$$
\begin{aligned}
& \phi_{1}(\xi, \eta)=\frac{\prod_{j=1}^{m} \Gamma\left(b_{j}-\beta_{j} \xi-B_{j} \eta\right) \prod_{j=1}^{n} \Gamma\left(1-a_{j}+\alpha_{j} \xi+A_{j} \eta\right)}{\sum_{i=1}^{r}\left[\prod_{j=n+1}^{p_{i}} \Gamma\left(a_{j i}-\alpha_{j i} \xi-A_{j i} \eta\right) \prod_{j=1}^{q_{i}} \Gamma\left(1-b_{j i}+\beta_{j i} \xi+B_{j i} \eta\right)\right.},
\end{aligned}
$$

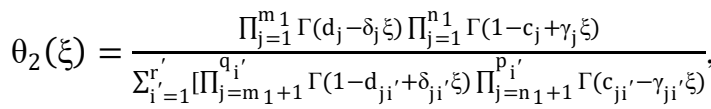

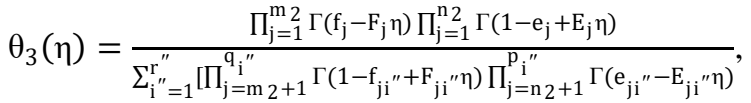

$\mathrm{x}$ and $\mathrm{y}$ are not equal to zero, and an empty product is interpreted as unity $\mathrm{p}_{\mathrm{i}}, \mathrm{p}_{\mathrm{i}^{\prime}}, \mathrm{p}_{\mathrm{i}^{\prime \prime}}, \mathrm{q}_{\mathrm{i}}, \mathrm{q}_{\mathrm{i}^{\prime}}, \mathrm{q}_{\mathrm{i}^{\prime \prime}}, \mathrm{m}, \mathrm{n}, \mathrm{n}_{1}$, $\mathrm{n}_{2}, \mathrm{n}_{\mathrm{j}}$ and $\mathrm{m}_{\mathrm{k}}$ are non negative integers such that $\mathrm{p}_{\mathrm{i}} \geq \mathrm{n} \geq 0, \mathrm{p}_{\mathrm{i}^{\prime}} \geq \mathrm{n}_{1} \geq 0, \mathrm{p}_{\mathrm{i}^{\prime \prime}} \geq \mathrm{n}_{2} \geq 0, \mathrm{q}_{\mathrm{i}} \geq \mathrm{m}>0$, $\mathrm{q}_{\mathrm{i}^{\prime}} \geq 0$, $\mathrm{q}_{\mathrm{i}^{\prime \prime}} \geq 0$, (i $\left.=1, \ldots, r ; i^{\prime}=1, \ldots, r^{\prime} ; i^{\prime \prime}=1, \ldots, r^{\prime \prime} ; k=1,2\right)$ also all the A's, $\alpha$ 's, B's, $\beta$ 's, $\gamma^{\prime}$ 's, $\delta$ 's, E's and F's are assumed to be positive quantities for standardization purpose; the definition of I-function of two variables given above will however, have a meaning even if some of these quantities are zero. The contour $\mathrm{L}_{1}$ is in the $\xi$-plane and runs from $-\omega \infty$ to $+\omega \infty$, with loops, if necessary, to ensure that the poles of $\Gamma\left(\mathrm{d}_{\mathrm{j}}-\delta_{\mathrm{j}} \xi\right)(\mathrm{j}=1$, $\mathrm{m}_{1}$ ) lie to the right, and the poles of $\Gamma\left(1-c_{j}+\gamma_{j} \xi\right)\left(j=1, \ldots, n_{1}\right), \Gamma\left(1-a_{j}+\alpha_{j} \xi+A_{j} \eta\right)(j=1, \ldots, n)$ to the left of the contour.

The contour $L_{2}$ is in the $\eta-$ plane and runs from $-\omega \infty$ to $+\omega \infty$, with loops, if necessary, to ensure that the poles of $\Gamma\left(f_{j}-F_{j} \eta\right) \quad\left(j=1, \ldots . ., n_{2}\right)$ lie to the right, and the poles of $\Gamma\left(1-e_{j}+E_{j} \eta\right)\left(j=1, \ldots, m_{2}\right), \Gamma\left(1-a_{j}+\right.$ $\left.\alpha_{j} \xi+A_{j} \eta\right)(j=1, \ldots, n)$ to the left of the contour. Also

$$
\begin{aligned}
& R^{\prime}=\sum_{\mathrm{j}=1}^{\mathrm{p}_{\mathrm{i}}} \alpha_{\mathrm{ji}}+\sum_{\mathrm{j}=1}^{\mathrm{p}_{\mathrm{i}}{ }^{\prime}} \gamma_{\mathrm{ji}}{ }^{\prime}-\sum_{\mathrm{j}=1}^{\mathrm{q}_{\mathrm{i}}} \beta_{\mathrm{ji}}-\sum_{\mathrm{j}=1}^{\mathrm{q}_{\mathrm{i}}{ }^{\prime}} \delta_{\mathrm{ji}}<0, \\
& S^{\prime}=\sum_{j=1}^{p_{i}} A_{j i}+\sum_{j=1}^{p_{i}^{\prime \prime}} E_{j i}{ }^{\prime \prime}-\sum_{j=1}^{q_{i}} B_{j i}-\sum_{j=1}^{q_{i}^{\prime \prime}} F \delta_{j i}<0, \\
& U=\sum_{j=n+1}^{\mathrm{p}_{\mathrm{i}}} \alpha_{\mathrm{ji}}-\sum_{\mathrm{j}=\mathrm{m}+1}^{\mathrm{q}_{\mathrm{i}}} \beta_{\mathrm{ji}}+\sum_{\mathrm{j}=1}^{\mathrm{m}_{1}} \delta_{\mathrm{j}}-\sum_{\mathrm{j}=\mathrm{m}_{1}+1}^{\mathrm{q}_{\mathrm{i}^{\prime}}} \delta_{\mathrm{ji}}{ }^{\prime}+\sum_{\mathrm{j}=1}^{\mathrm{n}_{1}} \gamma_{\mathrm{j}}-\sum_{\mathrm{j}=\mathrm{n}_{1}+1}^{\mathrm{p}_{\mathrm{i}^{\prime}}} \gamma_{\mathrm{ji}}>0, \\
& V=-\sum_{j=n+1}^{p_{i}} A_{j i}-\sum_{j=m+1}^{q_{i}} B_{j i}-\sum_{j=1}^{m_{2}} F_{j}-\sum_{j=m_{21}+1}^{q_{i}{ }^{\prime}} F_{j i}{ }^{\prime}+\sum_{j=1}^{n_{2}} E_{j}-\sum_{j=n_{2}+1}^{p_{i}{ }^{\prime \prime}} E_{j i}{ }^{\prime \prime}>0,
\end{aligned}
$$

and $|\arg \mathrm{x}|<1 / 2 \mathrm{U} \pi,|\arg \mathrm{y}|<1 / 2 \mathrm{~V} \pi$. 


\section{Result Required}

The following result are required in our present investigation:

From Rainville [2]:

$$
z \Gamma(z)=\Gamma(z+1) .
$$

\section{Main Result}

In this paper we will establish the following partial derivatives:

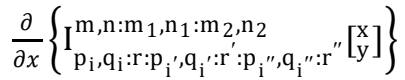

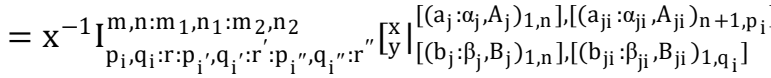

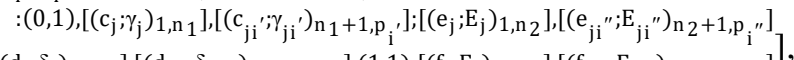

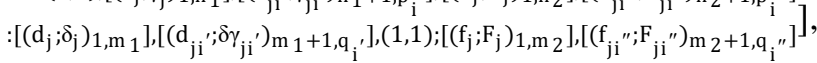

where $|\arg \mathrm{x}|<1 / 2 \mathrm{U} \pi,|\arg \mathrm{y}|<1 / 2 \mathrm{~V} \pi$, where $\mathrm{U}$ and $\mathrm{V}$ are given in (2) and (3) respectively.

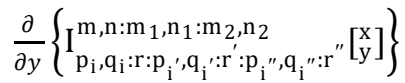

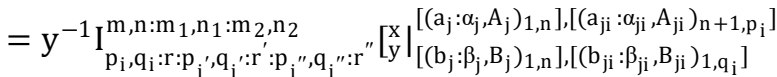

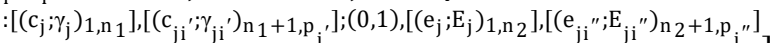

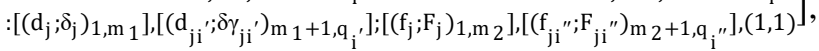

where $|\arg \mathrm{x}|<1 / 2 \mathrm{U} \pi,|\arg \mathrm{y}|<1 / 2 \mathrm{~V} \pi$, where $\mathrm{U}$ and $\mathrm{V}$ are given in (2) and (3) respectively.

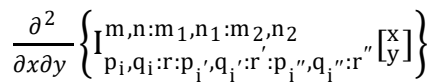

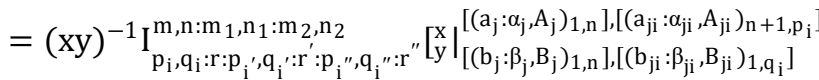

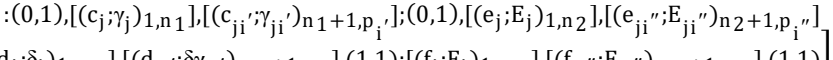

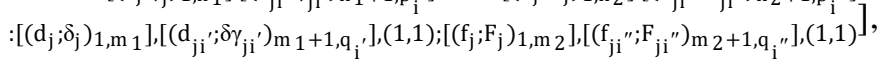

where $|\arg \mathrm{x}|<1 / 2 \mathrm{U} \pi,|\arg \mathrm{y}|<1 / 2 \mathrm{~V} \pi$, where $\mathrm{U}$ and $\mathrm{V}$ are given in (2) and (3) respectively.

Proof:

To establish (5), we use for the generalized I-function of two variables Mellin-Barnes types of contour integral as given in (1), on the left-hand side of (5), change the order of integration and derivative (which is justified under the conditions given with (5)), we then obtain

$$
\begin{aligned}
\text { Left-hand side of }(5)= & \frac{(-1)}{4 \pi^{2}} \int_{\mathrm{L}_{1}} \int_{\mathrm{L}_{2}} \phi_{1}(\xi, \eta) \theta_{2}(\xi) \theta_{3}(\eta)\left[\frac{\partial}{\partial x} \mathrm{x}^{\xi}\right] \mathrm{y}^{\eta} \mathrm{d} \xi \mathrm{d} \eta \\
& =\frac{(-1)}{4 \pi^{2}} \int_{\mathrm{L}_{1}} \int_{\mathrm{L}_{2}} \phi_{1}(\xi, \eta) \theta_{2}(\xi) \theta_{3}(\eta)\left[\xi \mathrm{x}^{\xi-1}\right] \mathrm{y}^{\eta} \mathrm{d} \xi \mathrm{d} \eta \\
& =\frac{(-1)}{4 \pi^{2}} \int_{\mathrm{L}_{1}} \int_{\mathrm{L}_{2}} \phi_{1}(\xi, \eta) \theta_{2}(\xi) \theta_{3}(\eta)\left[\frac{\xi \Gamma(\xi)}{\Gamma(\xi)} x^{\xi-1}\right] \mathrm{y}^{\eta} \mathrm{d} \xi \mathrm{d} \eta
\end{aligned}
$$

Now using the result (4) and interpreting the resulting contour integral as the generalized I-function of two variables, we once get the right-hand side of (5). Proceeding on the similar way, the results (6) and (7) can be obtained.

\section{Special Cases}

On choosing $\mathrm{m}=0$ main results, we get following partial derivatives in terms of I-function of two variables:

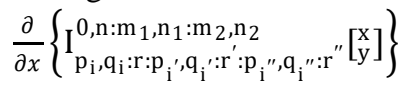

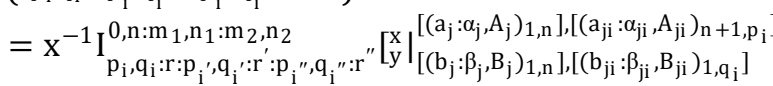

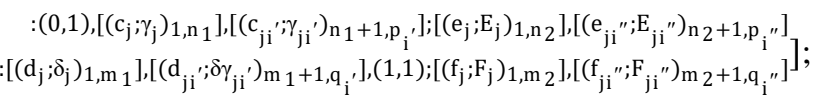




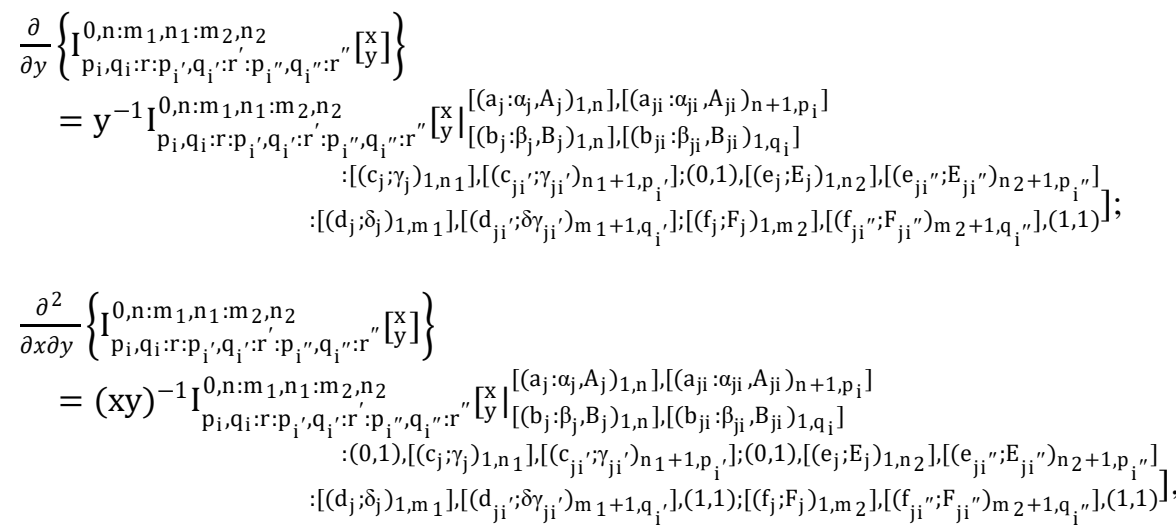

where $|\arg \mathrm{x}|<1 / 2 \mathrm{U}^{\prime} \pi,|\arg \mathrm{y}|<1 / 2 \mathrm{~V}^{\prime} \pi$, where $\mathrm{U}^{\prime}$ and $\mathrm{V}^{\prime}$ are given as follows respectively:

$U^{\prime}=\sum_{\mathrm{j}=\mathrm{n}+1}^{\mathrm{p}_{\mathrm{i}}} \alpha_{\mathrm{ji}}-\sum_{\mathrm{j}=1}^{\mathrm{q}_{\mathrm{i}}} \beta_{\mathrm{ji}}+\sum_{\mathrm{j}=1}^{\mathrm{m}_{1}} \delta_{\mathrm{j}}-\sum_{\mathrm{j}=\mathrm{m}_{1}+1}^{\mathrm{q}^{\prime}} \delta_{\mathrm{ji}}+\sum_{\mathrm{j}=1}^{\mathrm{n}_{1}} \gamma_{\mathrm{j}}-\sum_{\mathrm{j}=\mathrm{n}_{1}+1}^{\mathrm{p}_{\mathrm{j}^{\prime}}} \gamma_{\mathrm{ji}}>0$,

$V^{\prime}=-\sum_{j=n+1}^{p_{i}} A_{j i}-\sum_{j=1}^{q_{i}} B_{j i}-\sum_{j=1}^{m_{2}} F_{j}-\sum_{j=m_{21}+1}^{q_{i}{ }^{\prime \prime}} F_{j i}{ }^{\prime \prime}+\sum_{j=1}^{n_{2}} E_{j}-\sum_{j=n_{2}+1}^{p_{i}{ }^{\prime \prime}} E_{j i}{ }^{\prime \prime}>0$,

\section{References}

[1]. Goyal, Anil and Agrawal,R.D. Integral involving the product of I-function of two variables, Journal of M.A.C.T. Vol. 28 P 147155(1995)

[2]. Rainville, E. D.: Special Functions, Macmillan, NewYork, 1960. 